Available online at GSC Online Press Directory

GSC Biological and Pharmaceutical Sciences

e-ISSN: 2581-3250, CODEN (USA): GBPSC2

Journal homepage: https://www.gsconlinepress.com/journals/gscbps

(RESEARCH ARTICLE)

\title{
Anesthetic and surgical experience in a tertiary hospital in a setting of fossil-fuel explosion resulting in mass casualty burn injury
}

\author{
Efu Michael ${ }^{1,}{ }^{*}$, Denen Akaa Priscilla ${ }^{2}$, Ahachi Chukwukadibia ${ }^{2}$ and Ojo Babarinde ${ }^{3}$ \\ ${ }^{1}$ Department of Anesthesia, College of Health Sciences, Benue State University, Makurdi, Nigeria. \\ ${ }^{2}$ Department of Surgery, College of Health Sciences, Benue State University, Makurdi, Nigeria. \\ ${ }^{3}$ Department of Anatomical pathology, College of Health Sciences, Benue State University, Makurdi, Nigeria.
}

Publication history: Received on 11 May 2020; revised on 28 May 2020; accepted on 19 June 2020

Article DOI: https://doi.org/10.30574/gscbps.2020.11.3.0138

\begin{abstract}
A mass casualty flame burn injury involving seventeen patients occurred in Benue State, Nigeria in 2019 when a petrol tanker fell, and exploded as villagers at Ahumbe were scooping the petrol. An unidentified number of people were burned to death at the scene of the incident. The study was conducted to highlight the anesthetic and surgical experience gained in the management of these cases in a temporary emergency burn unit in Benue State University Hospital (BSUTH), Makurdi. Seventeen case files of eligible patients were retrieved from the Records Department. Relevant information were extracted from the patients' files and entered into a prepared proforma. The data collected were analyzed using SPSS version 25. A total of 17 patients' files were evaluated. There were 13 male patient's representing $76.5 \%$ and 4 females making up $23.5 \%$ of the study population, with male to female ratio of 3.3:1. The age bracket mostly affected was 21 to 30 years with 9 constituting $53.0 \%$ of the study population. Patients with mixed thickness burn were 12 accounting for $70.6 \%$ of the study population, full thickness and superficial burn were 3 and 2 making up $17.6 \%$ and $11.7 \%$ respectively. The least percentage total body surface area (TBSA) of burn was 8 and the highest was 91 , with mean of $40.1 \pm 15.9$. Seven patients came to our facility by way of referral from Federal Medical Centre (FMC) Makurdi, accounting for $41.2 \%$ of the study population. Most of the patients belonged to ASA II with 13 in number making up $76.5 \%$ of the study group. All the patients had meshed split thickness skin graft (SSG). A total of 19 anesthetic techniques were employed. Of these, the highest was general anesthesia (GA) with tracheal intubation and mechanical ventilation with 13 accounting for $68.4 \%$ of the study population. Of other therapies instituted, physiotherapy was done 16 times accounting for $64 \%$ of the variables. Sixteen (94.1\%) patients had $100 \%$ grafts take while one (5.9\%) had $97 \%$ graft take. Unfortunate as the incident of mass casualty burn injuries following the fossil-fuel explosion was, it brought about an indelible experience in the anesthetic and surgical management of these patients. The intervention by Médecins Sans Frontières (MSF) resulted in the availability of both anesthetic and surgical choices of procedures with most patients undergoing GA with tracheal intubation and mechanical ventilation and all the patients having meshed split thickness skin graft with good outcome.
\end{abstract}

Keywords: Fossil-fuel; Explosion; Mass casualty; Burn; Injury

\section{Introduction}

On July $1^{\text {st }} 2019$, a petrol tanker loaded with premium motor spirit (PMS), a fossil-fuel, fell down accidentally in a village called Ahumbe, a suburb of Aliade, Benue State, spilling its content. Owing to pervading economic hardship and in spite of repeated warnings from constituted authorities, the villagers took risk and began scooping the spilled fuel which exploded and burst into flames resulting in mass casualty burn injury.

\footnotetext{
* Corresponding author: Efu Michael
} 
Burned patients suffer direct thermal injury to the body and airway and may inhale smoke resulting in carbon monoxide $(\mathrm{CO})$ and cyanide $(\mathrm{CN})$ poisoning. Extensive fluid loss into the dermis, blisters and denuded skin surfaces is usual. (Yentis et al [1]) Morbidity and mortality following burn is, thus, not uncommon.

In the United States approximately 450,000 people seek treatment for burn injury each year, of whom 40,000 are hospitalized and 3,400 die. (Bittner et al [2]) Majority of these patients present in emergency rooms of hospitals without a burn center. Initial care of patients with serious burn injury presents challenges in airway management, vascular access and hemodynamic and pulmonary support [2].

A number of people were burned to death at scene of the incident. Some of those that sustained less severe injuries found their way to nearby hospitals/clinics for treatment. While some of those that required more intensive treatment came directly to our facility, BSUTH, others were transferred to us from other centers because of intervention by Médecins Sans Frontières (MSF) in setting up a temporary burn unit, thus making it the centre for the management of these casualties. Médecins Sans Frontières (Doctors Without Borders Inc.) an international independent medical humanitarian organization, not only provided surgical equipment for use by surgeons, they also equipped a theatre providing an anesthetic machine with a functional ventilator. Furthermore, they opened a temporary burn unit for the proper pre-operative and post-operative management of these patients. The equipment, technical and personnel support they provided made possible the anesthetic and surgical procedures hitherto desirable but unavailable, to be undertaken with a great deal of ease.

This study was undertaken to showcase our anesthetic and surgical experiences in the management of the patients.

\section{Methodology}

\subsection{Study Setting}

This was a retrospective study in which a total of 17 patients that underwent surgeries following a fossil-fuel explosion were evaluated. The study was undertaken in BSUTH, Makurdi, a 350 bedded hospital situated in the capital city of Benue Sate, North Central Nigeria.

\subsection{Ethical Considerations}

The approval of the BSUTH research and ethical committee was sought and obtained.

\subsection{Eligibility}

- Inclusion Criteria.

- Seventeen patients who underwent SSG in BSUTH as a result of the explosion between July and October 2019 were evaluated.

- Exclusion Criteria

- Surgeries other than those undertaken as a direct result of the explosion were excluded.

\subsection{Procedure}

Seventeen case files of eligible patients were retrieved from the records department of BSUTH after an application was approved. Relevant information were extracted from the patients' files and transferred into a prepared proforma. Data collected included age, sex, pre-operative diagnosis, percentage burns, American Society of Anesthesiologists physical status classification (ASA), where patients were transferred from, surgical procedure undertaken, anesthetic technique employed, complications of the techniques and the management of such complications. Data on other therapies instituted as well as outcome of surgical treatment were collected. The data collected were analyzed using SPSS version 25.

\section{Results}

A total of 17 patients' files were evaluated. There were 13 male patient's representing $76.5 \%$ and 4 females making up $23.5 \%$ of the study population, with male to female ratio of 3.3:1. The age bracket mostly affected was 21 to 30 years constituting $9(53.0 \%)$ of the study population (Fig. 1). 


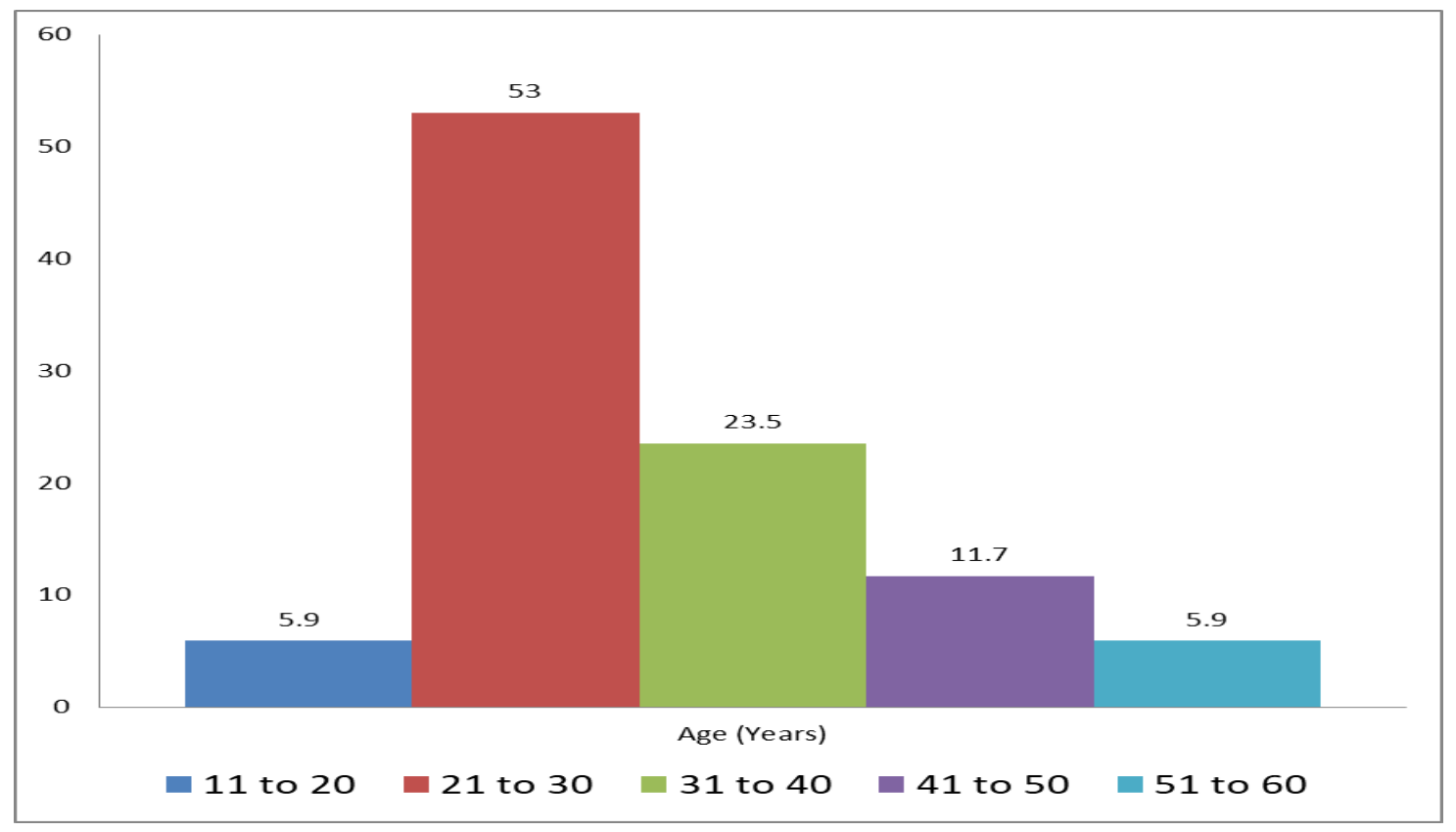

Figure 1 Histogram showing age group (bracket) of patients (\%)

Patients with mixed thickness burn were 12 accounting for $70.6 \%$ of the study population, full thickness and superficial burn were 3 and 2 making up $17.6 \%$ and $11.7 \%$ respectively. The least percentage total body surface area (TBSA) of burn was 8 and the highest was 91 , with mean of $40.1 \pm 15.9$.

The highest figure of 7 patients came to our facility by way of referral from Federal Medical Centre Makurdi, accounting for $41.2 \%$ of the study population. Three patients came directly to BSUTH representing $17.6 \%$ of the study population. Other hospital referrals to BSUTH are in table 1.

Table 1 Where patients were referred from to BSUTH.

\begin{tabular}{lll}
\hline Variable & Frequency ( N=17) & Percentage (\%) \\
\hline FMC, Makurdi & 7 & 41.2 \\
Direct to BSUTH & 3 & 17.6 \\
St. Vincent Hospital, Aliade & 3 & 17.6 \\
General Hospital, Aliade & 2 & 11.7 \\
Bishop Murray Hospital, Makurdi & 1 & 5.9 \\
Nigeria Air Force Hospital, Makurdi & 1 & 5.9 \\
\hline
\end{tabular}

Most of the patients belonged to the American Society of Anesthesiologists physical status classification (ASA) II with 13 making up 76.5\% of the study group. Other ASA grading of patients are in figure 2. 


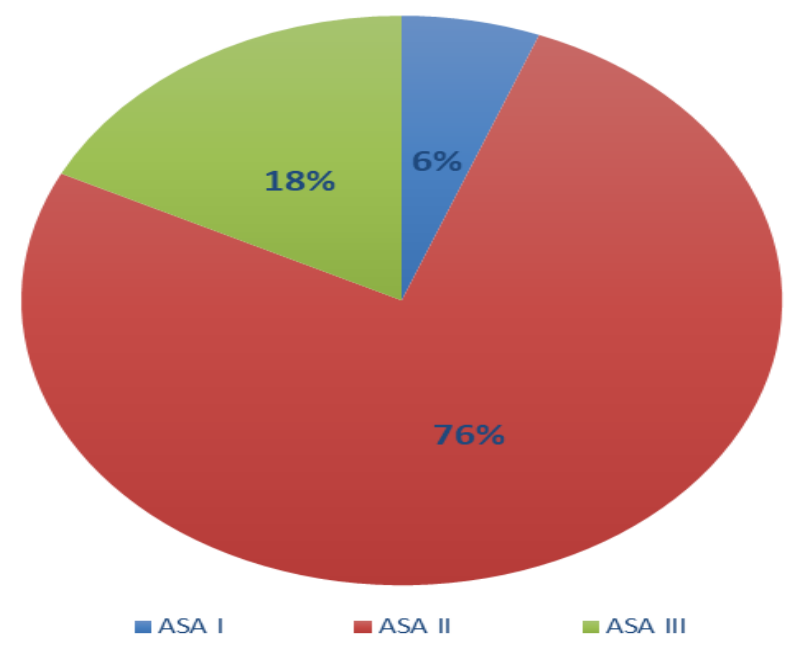

Figure 2 Pie chart illustrating ASA classification of patients (\%)

A total of 19 anesthetic techniques were employed. Majority of the patients underwent general anesthesia (GA) with tracheal intubation and mechanical ventilation. They were 13 accounting for $68.4 \%$ of the study population. Other anesthetic techniques employed are as on table 2.

Table 2 Anesthetic techniques employed

\begin{tabular}{|c|c|c|c|}
\hline Variable & & Frequency $(\mathrm{N}=19)$ & Percentage (\%) \\
\hline \multicolumn{4}{|l|}{ Anaesthetic Technique } \\
\hline $\begin{array}{l}\text { General Anaesthesia } \\
\text { intubation + ventilation }\end{array}$ & with tracheal & 13 & 68.4 \\
\hline Sub-arachnoid block & & 5 & 26.3 \\
\hline Local infiltration & & 1 & 5.3 \\
\hline
\end{tabular}

All the patients had meshed split skin graft (SSG)

Other therapies were employed singly or in combination. Of these physiotherapy was done 16 times accounting for $64 \%$ of the variables. This was followed by blood transfusion 5 (20\%). The rest include Ringers lactate infusion $3(12 \%)$ and admission into the intensive care unit (ICU) 1 (4\%).

While 16 patients $(94.1 \%)$ recorded $100 \%$ graft take, 1 patient (5.9\%) had $97 \%$ graft take. There were no complications recorded with any of the anesthetic techniques employed.

\section{Discussion}

Our study has shown that almost all the victims of this disaster who came for treatment were young, 0 to 50 years constituting 94.1\%. Youths are more likely to venture into risky acts such as scooping flammable substances like petrol from a fallen tanker as was the case here. Unemployment in the country is high (up to $38 \%$ in the second quarter of 2018) and idle youths could resort to cheap, quick and risky means to make money at all cost to take care of their feeding and other needs. Males injured were more in number, $76.5 \%$ compared to females. Men are invariably more likely to venture into dangerous acts than women as demonstrated here.

Referral system was appropriately utilized to ensure the burn patients were adequately managed in a centre well equipped with facilities and personnel for the treatment. Most of the patients (82.4\%) were admitted and resuscitated at hospitals close to the scene of the accident before referral to BSUTH. 
Majority (76\%) of the patients belonged to ASA II status. This is because most of them were brought in after initial management in various hospitals of admission at the time of the acute phase of their injuries such that they had stabilized sufficiently on arrival at BSUTH.

Of the 19 anesthetic techniques employed, majority (68\%) of the patients underwent GA with tracheal intubation and mechanical ventilation. Atracurium, an intermediate acting non-depolarising muscle relaxant was utilized for the purpose of tracheal intubation, and patients were put on the ventilator immediately after intubation. Suxamethonium was avoided because of its effect of increasing serum potassium in burn patients. In burn patients, exposure to suxamethonium can cause exaggerated hyperkalemia response, which can result in cardiac arrest. The current recommendation is to shun suxamethonium administration in patients 48 hours after burn injury. (Martyn JA and MacLennan et al [3.4]) The large number of GA that was used is a reflection of the high percentage TBSA of burn necessitating grafting of large sites on the body as well as requiring much donor skin.

The five cases that underwent SAB had both their injuries and donor sites restricted to the lower extremities. It is worthy of note that while one of the patients had a failed spinal and was converted to GA, one other had infiltration of a local anesthetic agent along with SAB.

All the patients had meshed split thickness skin graft (SSG). This was made possible because of the provision of the meshing machine by MSF leading to a pleasant surgical experience.

The burn patients had other forms of therapy instituted. Physiotherapy was carried out 16 times representing $64 \%$ of the variables. This is because physiotherapy is usually the tool mostly employed in burn injury to prevent contractures which are a common complication. Blood transfusion was carried out 5 times accounting for $20 \%$ of the variables. Burn patients commonly develop anemia and may require blood transfusion intra-operatively as a result of intra-operative blood loss. Acute blood loss anemia occurs during the first 1 to 2 weeks after burn injury. Blood is lost directly from the thermal injury and from dressing of the wounds. Other causes of anemia may be from concurrent traumatic injury, red blood cell sequestration, (Loebl et al [5]) and direct erythrocyte damage. (Kimber and Lander [6])

The three patients that came in directly had their resuscitation done at BSUTH. This accounted for the administration of Ringers Lactate in them since one of the most important modalities for initial treatment is fluid resuscitation. Fast and effective intravascular volume replenishment is crucial for mitigation of burn shock. Delayed or insufficient fluid replacement results in hypovolemia, tissue hypoperfusion, shock and multiple organ failure. (Barrow et al [7]) Inadequate fluid resuscitation can also worsen the effects of smoke inhalation injury. (Herndon et al and Alvarado et al $[8,9]$.

With regards to the outcome of the skin grafts, all but one had $100 \%$ graft take. This is an attestation to the enhanced anesthetic and surgical procedures occasioned by highly skilled personnel and the intervention of MSF in providing an emergency well equipped temporary burn unit and theatre.

\section{Conclusion}

Unfortunate as the incident of mass casualty burn injuries following the fossil-fuel explosion was, it brought about an indelible experience in the anesthetic and surgical management of these patients. The intervention by MSF resulted in the availability of both anesthetic and surgical choices of procedures with most patients undergoing GA with tracheal intubation and mechanical ventilation and all the patients having meshed split thickness skin graft with good outcome.

\section{Compliance with ethical standards}

\section{Acknowledgments}

I wish to register my appreciation to all my co-authors for their immense contributions towards the realization of this publication. Let me also express my gratitude to my office assistants, Dominic Iorhember and Amos Tyosongo for their immeasurable all round assistance and the clerical work of this publication.

\section{Conflict of interest:}

None. 


\section{References}

[1] Yentis SM, Hirsh NP and Smith GB. (2013). Anaesthesia and intensive care A-Z: An Encyclopaedia of Principles and Practice, 5th edition. Edinburgh, Elsevier Butterworth Heinemann, 91.

[2] Bittner EA, Shank E, Woodson L and Jeevendra Martyn JA. (2015). Acute and Perioperative Care of the BurnInjured Patient. Anesth, 122(2), 448-464.

[3] Martyn JA. (1999). Succinylcholine hyperkalemia after burns (letter). Anesthesiology, 91, 321-2.

[4] MacLennan N, Heimbach DM and Cullen BF. (1998). Anesthesia for major thermal injury. Anesthesiology, 89, 749-70.

[5] Loebl EC, Marvin JA, Curreri W and Baxter CR. (1974). Erythrocyte survival following thermal injury. J. Surg Res, 16, 96-101.

[6] Kimber RJ and Lander H. (1964). The effect of heat on human red cell morphology, fragility, and subsequent survival in vivo. J Lab Clin Med, 64:922-33.

[7] Barrow RE, Jeschke MG and Herndon DN. (2000). Early fluid resuscitation improves outcomes in severely burned children. Resuscitation, 45, 91-6.

[8] Herndon DN, Traber DL and Traber LD. (1986). The effect of resuscitation on inhalation injury. Surgery, 100, 248-51.

[9] Alvarado R, Chung KK, Cancio LC and Wolf SE. (2009).Burn resuscitation. Burns, 35, 4-14.

\section{How to cite this article}

Efu M, Denen Akaa P, Ahachi C and Ojo B. (2020). Anesthetic and surgical experience in a tertiary hospital in a setting of fossil-fuel explosion resulting in mass casualty burn injury. GSC Biological and Pharmaceutical Sciences, 11(3), 75-80. 